\title{
MODEL FOR PREPARING RAJABHAT UNIVERSITY STUDENTS DEVELOPMENT IN THE CENTRAL REGION FOR THE ASEAN COMMUNITY
}

\author{
Thitiporn Pichayakul \\ Asst. Prof. Dr. Thitiporn Pichayakul and Research Team / Valaya Alongkorn Rajabhat University \\ under the Royal Patronage
}

\begin{abstract}
This research aimed to 1. to develop models of student development for Rajabhat Universities in the central region to prepare for ASEAN Community and 2 to study effectiveness of the models used for developing students at Rajabhat Universities in the central region. The results showed that there were four procedures in the student development model for Rajabhat Universities in the central Regions 1. Seeking Knowledge 2. Raising Awareness 3. Establishing Values 4. Self-Combining and Changing towards ASEAN Citizenship. The results from Confirmatory Factor Analysis influencing skills and affective domains of the students of Rajabhat Universities in the central region for the ASEAN Community showed that there were seven observable factors: Knowledge Understanding and Applicability (KNOWL), Self-development Skills (DELOPEM), Citizenship Skills (POPU), Pride of Thai Identity and ASEAN Uniqueness (PROUD), Acceptance of Cultural Diversity (CULTURE), Environmental Awareness (SURROUND), and Living in Peace (PEACE). The validation of the goodness of fitted of the model was at the 'Excellent' level and yielded a Chi-square (-test) of 13.58, at the Degrees of Freedom (df) of 8, the probability at 0.093. The Root Mean Square Error of Approximation was at 0.037 The resulted showed that the variables in the proposed model were consistent with the empirical data. Moreover, the Citizenship Skills (POPU) had the highest factor loading at 0.929 and the covariation with the skills and affective domains of the students of Rajabhat Universities in the central region for the ASEAN Community at $86.20(\mathrm{R} 2=0.862)$ significantly at .05 level.
\end{abstract}

Keywords: first keyword, second keyword, (Maximum five keywords)

\section{Introduction}

The guideline for conducting activities for preparing the university students for the ASEAN Community is critically essential for making an ASEAN citizen, as well as, a global citizen who is ready for all changes in the world and knowledgeable. They need to concern with various issues such as current political, economic, and socio-cultural situations, ASEAN Charter, ability to live with multicultural community, foreign language proficiency, citizenship skills, learning and development skills, positive attitudes towards the ASEAN Community, 'Good Governance' principles, peaceful means, pride of being a Thai and an ASEAN Citizen, and acceptance of religious and cultural diversity and living among others happily. As a result, Rajabhat Universities in the central region consisting of Valaya Alongkorn Rajabhat University under the Royal Patronage situated in Pathum Thani Province, Rambhai Barni Rajabhat University situated in Chanthaburi Province, Thepsatri Rajabhat University situated in Lopburi Province, Phranakorn Si Ayutthaya Rajabhat University situated in Phranakorn Si Ayutthaya Province, and Rajabhat Rajanagarindra University situated in Chachoengsao Province. Those Rajabhat universities are situated in the Bangkok Metropolitan Region with convenient public transportation, industrial parks, and large economic areas. Therefore, there is a lot of labor force both local and international (especially from the ASEAN countries) living and working in the area. Rajabhat Universities have worked together in order to be ready the most for moving towards the ASEAN Community by 2015 or B.E. 2558, for examples, the Rajabhat Universities have studied the current situations of their universities on educational provision which is as qualified as other countries, opinions of the Rajabht university community on this ASEAN association, preparations for moving towards the ASEAN Community, possible challenges and limitations, including solutions and recommendations (Council of Rajabhat University Presidents: http://www.rajabhatnetwork.com). According to the studies, it was found that Rajabhat universities have provided an opportunity for the students to learn about and both directly and indirectly experience identities and cultures of all ASEAN Countries according to the 
readiness of each university. Despite of a number of preparations and implementations, activities focusing on student development still lack a precise model to achieve the above goals. The researchers were, hence, interested in studying a development model for preparing Rajabhat University students in the central region for the ASEAN Community in order to use as a guideline for developing the students in terms of knowledge, skills, and attitudes towards the ASEAN Community.

\section{Objective of the Study}

- To develop model of student development for Rajabhat Universities in the central region to prepare for ASEAN Community.

- To study effectiveness of the model used for developing students at Rajabhat Universities in the central region.

\section{Scope of the Study}

The samples of the study were as follows:

1. Experts

1.1 The three Experts selected in this group are responsible for making policies for developing university students from the Ministry of Education: The Secretary of the Higher Education Commission, The Assistant Secretary to the Minister of Ministry of Education, A Committee of the Educational Reform and Human Resources Development, National Reform Council, the Chairman of Teachers Council Committee.

1.2 Another 15 experts in this group are responsible for making policies for developing Rajabhat University students such as experts in Rajabhat University council, and presidents, vice-presidents, as well as, assistants to the presidents of Rajabhat Universities who have taken the positions since 2007.

2. The officials or the practitioners who have worked on Rajabhat University student development in the central region since 2007 as follows;

2.110 Vice-presidents for Student Affairs

2..2 Directors of the Student Development Department

2.3 Officials of the Student Development Department of either the university or the faculties.

3. University Students which can be defined as Rajabhat University students in the central region who are studying during the academic semesters of 2014-2015

3.1 10 Student Presidents and Ministers of Student Councils

3.2 250 Rajabhat University students in the central region

\section{Variable of the Study}

The effectiveness of the model for preparing Rajabhat University students' development in the central region for the ASEAN community

\section{Definition of Terms}

1. Rajabhat University students in the Central Region Development can be defined as that Rajabhat Universities in the central region support Rajabhat Universities students in the central region to appropriately conduct activities focusing on intellectual, social, mental, physical, and ethical development in order to become desired graduates.

2. The readiness for the ASEAN Community is the state of readiness of the university students for the ASEAN Community. The three aspects of the readiness are knowledge, skills/process, and attitude.

3. A Development Model for Preparing Rajabhat University Students development in the central region for the ASEAN Community means components which are related to preparing Rajabhat University Students development in the central region for the ASEAN Community.

4. The Effectiveness of the Model for Preparing Rajabhat University Students development in the central region for the ASEAN Community. Confirmatory Factor Analysis or CFA was used for analysing the data collected from the study.

5. Rajabhat Universities in the central region means Valaya Alongkorn Rajabhat University under the Royal Patronage situated in Pathum Thani Province, Rambhai Barni Rajabhat University situated in Chanthaburi Province, Thepsatri Rajabhat University situated in Lopburi Province, Phranakorn Si Ayutthaya Rajabhat University situated in Phranakorn Si Ayutthaya Province, and Rajabhat Rajanagarindra University situated in Chachoengsao Province.

\section{Significance of the Study}

Rajabhat Universities in the central region has the effectiveness of the model for preparing Rajabhat University students development in the central region for the ASEAN Community and uses it as a 
guideline for developing the students' knowledge, skills, and attitude on moving towards the ASEAN Community.

\section{Research Methodology of the Study}

Phase 1

1. Studying concepts, theories, research studies related to a model for student development, the ASEAN Community, and 21st Century Skills.

Phase 2

2. Studying the currents situations on university student development in the central region using in-depth interview and interrogation with the experts and the officials responsible for student development of the Rajabhat University students in the central region and the students themselves.

3. Analyzing and synthesizing the above data to develop a conceptual framework for the development model for preparing Rajabhat University students development in the central region for the ASEAN Community. Phase 3

4. Drafting the development model for preparing Rajabhat University students development in the central region for the ASEAN Community.

5. This proposed development model should be tried out with a sample group of Rajabhat University students.

6. All data collected from the tryout of the development model for preparing the Rajabhat University students development in the central region for the ASEAN Community should be used to analyze.

7. The proposed development model should be finally revised in order to have a complete version of the development model for preparing Rajabhat University students in the central region for the ASEAN Community. Phase 4

8. The final version of the effectiveness of the model should be experimented in order to prove the achievement. Confirmatory Factor Analysis or CFA was used for analysing the data collected from the study.

\section{Conceptual Framework of the Model for Preparing Rajabhat University Students Development in the Central Region for the ASEAN Community}

\section{Research Framework}

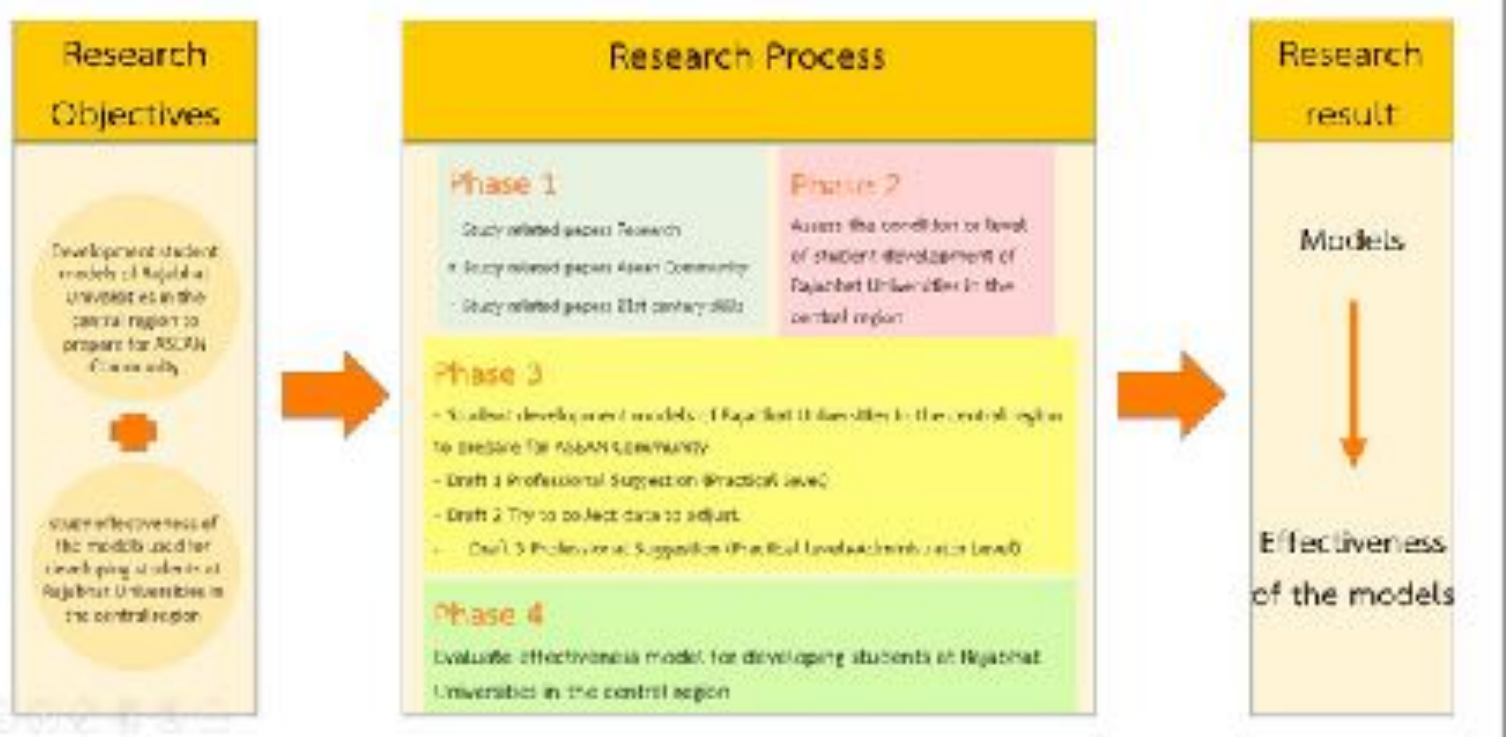

Figure 1: Conceptual Framework of the Development Model for Preparing Rajabhat University

\section{Research Findings}

Students in the Central Region for the ASEAN Community

The development model for preparing Rajabhat University students development in the central region for the ASEAN Community consists of the following principles, procedures, and processes.

The principle means implementations on Rajabhat University student development development in the central region for the ASEAN Community consisting of concepts of student development in the changing society, policies on developing students in the higher education level, and guidelines for developing students for the ASEAN Community. 


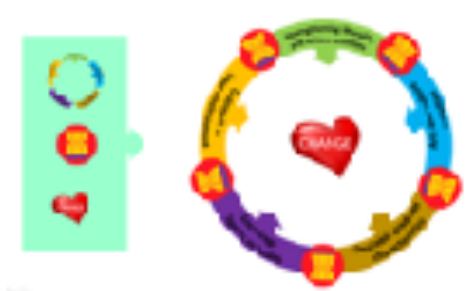

Figure 2: Concepts, Policies, and Guidelines for Developing the Students for the ASEAN Community

Principles

The principles for Rajabhat University student development in the central region for the ASEAN Community consist of the following concepts, policies, and guidelines.

The concepts of developing students in the changing society, enhancing learning, and encouraging the students to be aware of themselves, as well as, their capacity necessary for self-improvement including building their capacity to move forward to work with others, provide community services, and be the cause of positive changes.

The policies for developing university students specified by the Higher Education Commission emphasize on having all higher educational institutes conduct student activities covering five components of student development as follows.

Component 1: Moral and ethics

Component 2: Community services and environment preservation

Component 3: Sports or health

Component 4: Desirable characteristics of graduates

(specified by the institute)

Component 5: Arts and culture

In terms of the guideline for developing the students for the ASEAN Community, based on the review of literature, related studies, the in-depth interview with the experts who are responsible for making policies on university student development from the Ministry of Education, the interview with the experts who are responsible for making policies for developing Rajabhat University students, and the interview with the officials or the practitioners who have worked on Rajabhat University student development in the central region, it was found that in order to develop the university student for the ASEAN Community as equally and gracefully as other member countries, it is necessary to develop skills and cultivate specific characteristics for the Rajabhat University students in the central region to acquire the three aspects of readiness: Knowledge, Skill/Process, and Attitude.

The readiness on the knowledge means the readiness about the basic knowledge about ASEAN countries, political, economic, social, and cultural situations, as well as, the ASEAN Charter.

The readiness on skills/process means the readiness on basic skills, citizenship skills, social responsibility, learning and self-development skills.

The readiness on attitude means the readiness on being proud of their Thai identity/part of the ASEAN Community, being responsible for the ASEAN Community, being aware of and accepting the diversity of religions, persisting in the 'Good Governance' principles, peaceful means, and following the 'Sufficiency Economy Philosophy'.

\section{$\underline{\text { Steps }}$}

The four steps to follow the guideline for developing the students for the ASEAN Community are as follows.

Step 1 Seeking Knowledge

Step 2 Raising Awareness

Step 3 Establishing Value

Step 4 Integrating and Transforming to an ASEAN Citizen

\section{Process}

Step 1 Seeking Knowledge consists of 5 phases as follows 


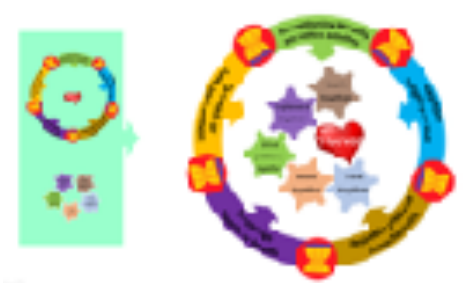

Figure 3: Step 1 Seeking Knowledge

Phase 1 Brainstorming (The students together identify a problem based on a current situation or the students' interest.)

Phase 2 Team-working (The students study to understand the selected problem as a team)

Phase 3 Collaborative Problem Solving (The students collaboratively share ideas on how to solve the selected problem, then, study, investigate, and analyze the data found for finding the best solution to the problem. Finally, they make plans and finalize the how to implement together.)

Phase 4 Implementing Together (The students implement the plan according to their assigned roles and responsibilities as planned together.)

Phase 5 Learning Together (The students share results of the implementation, as well as, learn from the others' sharing in order to adapt in a different situations in the future.)

Step 2 Raising Awareness consists of three aspects as follows.
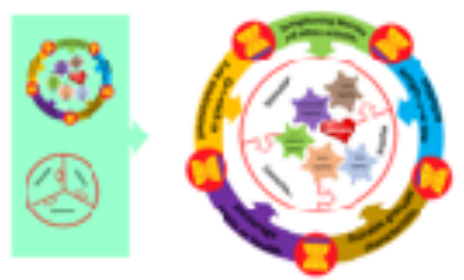

Figure 4: Step 2 Raising Awareness

Aspect 1 Activating critical thinking skills using questions

Aspect 2 Realizing the importance of different situations and issues together

Aspect 3 Practicing reasonably on their own in different situation.

Step 3 Establishing Value consists of three aspects as follows.
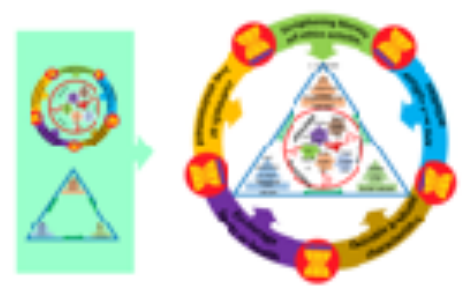

Figure 5: Step 3 Establishing Value

Aspect 1 Personal Value represents individual realization of roles and responsibilities.

Aspect 2 Group Value represents the collaboration, the shared goals, and the ability to discuss either agreements or disagreements with respects.

Aspect 3 Social/Community Value represents the ASEAN Citizenship.

Step 4 Integrating and Transforming to an ASEAN Citizen is a process of self-reflection based on the integration of knowledge, skills/process, and attitude in order to transform themselves to become a responsible ASEAN Citizen.

Submit Date: 10.07.2

Res

Copyright (C) T

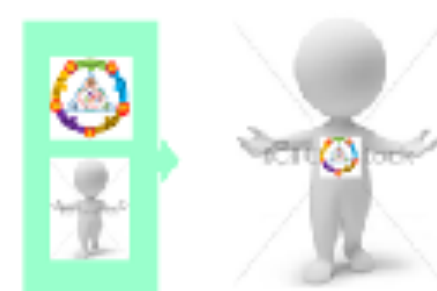

8, DOI NO: $10.7456 / 1080$ SSE/163

lecked by Turnitin

ign, Art and Communication 
Figure 6: Step 4 Integrating and transforming to an ASEAN Citizen

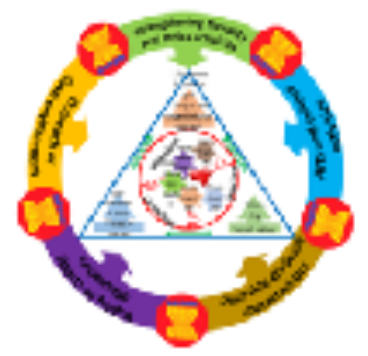

Figure 7: A Development Model for Preparing Rajabhat University Students in the Central Region for the ASEAN Community

To conclude, the Development Model for preparing the students development for the ASEAN Community as mentioned above can be used to develop the knowledge, skills/process, and attitude of the students, as a result, transform themselves effectively enough to move towards the ASEAN Community. Moreover, universities can use the model as a core guideline for conducting university activities focusing on developing the students to become a ready ASEAN, and of course global, citizen in the future.

Moreover, Confirmatory Factor Analysis or CFA was used for analysing the data collected from the study. In terms of the tool of the study, four aspects of desired characteristics were developed into 64 characteristics. These items were analysed by a group of experts with the results as followed; the Knowledge Aspect with a total of 10 characteristics (6 in the 'highly important' level and 4 in the 'moderately important' level), skill and Process Aspect with a total of 19 characteristics (18 in the 'highly important' level and 1 in the 'moderately important' level), and Affective Aspect with a total of 21 characteristics ( 20 in the 'highly important' level and 1 in the 'moderately important' level).

The results from Confirmatory Factor Analysis influencing skills and affective domains of the students of Rajabhat Universities in the central region for the ASEAN Community showed that there were seven observable factors: Knowledge Understanding and Applicability (KNOWL), Self-development Skills (DELOPEM), Citizenship Skills (POPU), Pride of Thai Identity and ASEAN Uniqueness (PROUD), Acceptance of Cultural Diversity (CULTURE), Environmental Awareness (SURROUND), and Living in Peace (PEACE).

The validation of the goodness of fitted of the model was at the 'Excellent' level and yielded a Chisquare (-test) of 13.58, at the Degrees of Freedom (df) of 8, the probability at 0.093 . The Goodness of Fit Index and the Adjust Goodness of Fit Index were at 0.992 and 0.973 respectively. The Root Mean Square Error of Approximation was at 0.037 and the Standardized Root Mean Square Residual was at 0.013 . From the above data shown, it revealed that (-test) $<2$ was at 1.697 and $\mathrm{p}$ was higher than .05 . The resulted showed that the variables in the proposed model were consistent with the empirical data.

In terms of the skills and affective domains of the students of Rajabhat Universities in the central region for the ASEAN Community, the seven observable factors: Knowledge Understanding and Applicability (KNOWL), Self-development Skills (DELOPEM), Citizenship Skills (POPU), Pride of Thai Identity and ASEAN Uniqueness (PROUD), Acceptance of Cultural Diversity (CULTURE), Environmental Awareness (SURROUND), and Living in Peace (PEACE) had the factor loading at $0.843,0.832,0.929,0.758,0.804,0.738$, and 0.316 respectively. Moreover, the Citizenship Skills (POPU) had the highest factor loading at 0.929 and the covariation with the skills and affective domains of the students of Rajabhat Universities in the central region for the ASEAN Community at $86.20(\mathrm{R} 2=0.862)$ significantly at .05 level.

\section{References}

Submit Date: 10.07.2018, Acceptance Date: 22.08.2018, DOI NO: 10.7456/1080SSE/163

Research Article - This article was checked by Turnitin

Copyright (C) The Turkish Online Journal of Design, Art and Communication 
Bureau of International Cooperation. (2015). Education: The Establishment of the ASEAN Community. From http://www.bic.moe.go.th/th/images/stories/book/other/ ASEAN/ed- bulldingASEANcommunity.pdf. Retrieved 25 February 20112.

Chickering A. W. \& Reisser, Linda. (1993). Education and Indentity.2 nd ed. San Francisco :JosseyBass.

Frederick, Robert W. (1959). The third Curricular. New York: Appleton-Century, Crofts.

Good, Carter V. (1970). Dictionary of Education. New York : Mc Grow-Hill Book.

Herbert, Stroup T. (1965). The Philosophy of student Activities, Minneapolis : University of Minneapolis Press.

Jitradup, A. S and others. (2012). Instructional Management Based on Educational

Reform. Report on Current Situations of Children and Youths The Bangkok Metropolitan Region.

Kijratporn, P. (2012). A Study of the Preparations of Rajabhat Universities for the ASEAN

Community in 2015. [Online]. From

www.lib.hcu.ac.th/asean/QuickReferenceGuide.pdf. (Retrieved 15 September 2013).

Kijratporn, P . (2011). "Directions of Multinational Education Provision for Preparing for

the ASEAN Community" 40 Rajabhat Universities During July 2011 and a Field Study on ASEAN Countries Between October and Novenber 2011 (The participants were categorized into 4 groups.) http://www.rajabhatnetwork.com or http://www.rajabhat2011.or.th)

Ministry of Education of the Kingdom of Thailand. (2012). Ministry of Education has

launched a policy in a conference on 23 August 2012.

www.203.172.142.8/en/index.php?option=com content...4... (Retrieved 17 February 2013)

Ministry of Foreign Affairs of the Kingdom of Thailand. Department of ASEAN Affairs. (2009).

ASEAN Diary. Bangkok: Animation.

Ngammongkholwong, S. (2015). ASEAN ICT Policy: Higher Education Strategic Enhancing

Toward the AEC 2015. Bachelor's Degree in Economic Science. Sukhothai

Thammathirat Open University.

Niyamajan, R. (2012). Implementations of Higher Educational Institutes under the

Context of the ASEAN Community. Office of Educational Quality Development. Bangkok University.

Pongsriwat, S. (2006). Social Change Model of Leadership. From http://suthep.ricr.ac.th.

Retrieved 23 April 2006.

Rummler, Geary A., Ramias, Alan J. and Richard A. Rummler (2006). "Potential Pitfalls

on the Road to a Process Managed Organization (PMO): Part 1: The Organization as System Lens" BPTrend, November.

Rupavijetra, P. (2012). Developing Students to Have Knowledge, Understanding on

Cross-cultural Management and Occupational Planning toward the ASEAN Community and International Level. Business Administration Faculty of Education Chiang Mai University.

Settakorn, V. (2014). The Preparation for the ASEAN Community: Problems and

Proposals in Developing Higher Education in Thailand.

Sookpotharom, P. (2015). Capacity Building of Personnel and Students for the ASEAN

Community in 2015. The Center for Cooperative Education and Career Development Bangkok University.

Tongroach, P. (2013). Skills/Process of ASEAN Students. Document of the 2012 Annual

Conference of the Office of Higher Educational Commission at Muang Thong Thani. p 56-58.

What Does ASEAN Offer You?. (2552). ASEAN Mutual Recognition Arrangements. ASEAN

Association-Thailand News. 1st Year (Second Issue), $p 8$.

Williamson, E.G. (1961). Student Personnel Services in Colleges and Universities.New York : Mc Graw - Hill. 